\title{
Outcomes Associated with Planned Home and Planned Hospital Births in Low-Risk Women Attended by Midwives in Ontario, Canada, 2003-2006: A Retrospective Cohort Study
}

\author{
Eileen K. Hutton, PhD, Angela H. Reitsma, BSc, BHSc(Midwifery), and \\ Karyn Kaufman, DrPH
}

\begin{abstract}
Background: Midwives in Ontario, Canada, provide care in the home and hospital and are required to submit data for all births to the Ontario Ministry of Health database. The purpose of this study was to compare maternal and perinatal/neonatal mortality and morbidity and intrapartum intervention rates for women attended by Ontario midwives who planned a home birth compared with similar low-risk women who planned a hospital birth between 2003 and 2006. Methods: The database provided outcomes for all women planning a home birth at the onset of labor $(\mathrm{n}=6,692)$ and for a cohort, stratified by parity, of similar low-risk women planning a hospital birth. Results: The rate of perinatal and neonatal mortality was very low $(1 / 1,000)$ for both groups, and no difference was shown between groups in perinatal and neonatal mortality or serious morbidity (2.4\% vs 2.8\%; relative risk [RR], 95\% confidence intervals [CI]: 0.84 [0.68-1.03]). No maternal deaths were reported. All measures of serious maternal morbidity were lower in the planned home birth group as were rates for all interventions including cesarean section (5.2\% vs 8.1\%; RR [95\% CI]: 0.64 [0.56, 0.73]). Nulliparas were less likely to deliver at home, and had higher rates of ambulance transport from home to hospital than multiparas planning home birth and had rates of intervention and outcomes similar to, or lower than, nulliparas planning hospital births. Conclusions: Midwives who were integrated into the health care system with good access to emergency services, consultation, and transfer of care provided care resulting in favorable outcomes for women planning both home or hospital births. (BIRTH 36:3 September 2009)
\end{abstract}

Key words: birth outcomes, cesarean section rates, home birth, midwifery care

Midwives in Ontario, Canada, provide care to low-risk women in a model of continuity or case-based care whereby a woman is attended by the same small group of midwives throughout pregnancy, birth, and the postpartum period. Women who meet selective criteria have the choice of a hospital birth or a planned home birth.
Midwives are expected to attend both home and hospital births to the extent that maintenance of registration with the regulatory college depends on a record of providing care in both settings.

Midwives are well integrated into the Ontario health care system; they have admission and discharge
Eileen K. Hutton is an Assistant Dean, Faculty of Health Sciences, Director Midwifery Education Program and Associate Professor in the Department of Obstetrics and Gynecology, McMaster University, Hamilton; Angela H. Reitsma is a Registered Midwife, Practicing Member at The Hamilton Midwives, Hamilton; and Karyn Kaufman is a Professor Emeritus Faculty of Health Sciences, McMaster University, Hamilton, Ontario, Canada.
Address correspondence to Dr. Eileen K. Hutton, McMaster University Midwifery Program, 1200 Main Street West, MDCL 2210, Hamilton, Ontario, Canada L8N $3 Z 5$.

Accepted March 23, 2009

(c) 2009, Copyright the Authors

Journal compilation @ 2009, Wiley Periodicals, Inc. 
privileges at their local hospital(s), and access to other health care providers for consultation or transfer of care as required. Two midwives are in attendance at births either in the home or in the hospital. The regulatory body, the College of Midwives of Ontario, sets out eligibility criteria for a home birth: women with twin, breech, or medically complicated pregnancies; with more than one previous cesarean section; or with gestation less than 37 weeks or more than 43 weeks at labor onset are ineligible. The college also prescribes the prenatal, intrapartum, and postpartum conditions for which consultation and transfer of care to a physician are mandatory $(1,2)$. Random practice audits are undertaken by the College of Midwives to ensure that standards and regulations are followed.

We sought to compare the outcomes of home and hospital births to inform the midwifery profession and the wider obstetric community, because birth at home remains controversial (3-9), and practitioners are subjected to criticism for attending home births (10). Although a single study cannot provide a definitive conclusion about the relative safety of birth setting, we thought it was important to assess the relatively recent experience within Ontario.

Evaluating the outcomes of home births poses several challenges. Because adverse outcomes are infrequent, large samples are needed to detect important differences; however, the number of births occurring at home is not large in most Western countries. Studies of home birth have been limited by sample size (4,11-24); absence of a comparison group (15,18,20-22,25-30); comparison with care provided by other practitioners $(17,23,24,29,31,32)$; use of self-reporting survey methods $(25,27,30)$; or inclusion of both planned and unplanned home births $(31,33)$.

Midwifery care in Ontario is part of publicly funded health care in the province. All midwives are required to submit a "client tracking form," which includes prenatal, intrapartum, and postpartum information for each woman in care. A database of midwifery care has been systematically compiled at the Ontario Ministry of Health. Since 2003, the submission of data has been tied to reimbursement, which together with ongoing audit and adjustment for inconsistent information virtually ensures a complete database.

During the study period (2003-2006), approximately 130,000 births (34) per year were reported in Ontario, with midwives attending about $8,600(6.6 \%)$ births annually. Actual home births accounted for 1.6 percent of the total provincial births and 25 percent of midwifeattended births (35).

The purpose of this study was to compare maternal and perinatal/neonatal mortality and morbidity and intrapartum intervention rates for women attended by Ontario midwives who planned a home birth, compared with similar low-risk women who planned a hospital birth between 2003 and 2006.

\section{Methods}

The Ministry of Health database of midwifery care was used to undertake a retrospective cohort study of 13,384 midwife-attended births that occurred between April 1, 2003, and March 31, 2006, to compare the outcomes for all women who planned a home birth $(n=6,692)$ at the outset of labor with a comparable low-risk group of women who planned a hospital birth at the outset of labor. All outcomes were analyzed according to the planned place of birth irrespective of actual birth setting. The groups were matched with respect to parity and previous lower segment cesarean section. Midwives registered with and regulated by the College of Midwives in Ontario attended all births included in the study. Ethics approval for the project was received from McMaster University Research Ethics Board.

\section{Selection of Study Groups}

Women discuss with their midwives their preference for place of birth at several points during the pregnancy, and

Table 1. Details of Allocation of 419 Records Inconsistent with Home Birth Criteria

\begin{tabular}{lll}
\hline Record Allocation & Record Details & $\begin{array}{c}\text { Number of } \\
\text { Cases }\end{array}$ \\
\hline Retained in primary analysis $(n=74)$ & Breech delivering at home or transferred in labor & 13 \\
& Preterm $\geqslant 35 \mathrm{wk}$ & 20 \\
Removed from any analysis $(n=90)$ & Antenatal transfer of care with possible return to midwifery care & 41 \\
& Breech with antenatal transfer of care and elective cesarean section & 36 \\
& Very preterm $\leqslant 28$ wk & Antenatal transfer of care for conditions judged to be permanent \\
Retained for sensitivity analysis $(n=255)$ & Breech with hospital delivery; no known transport in labor & 29 \\
& Preterm $<35$ wk; $>28$ wk & 30 \\
& Antenatal transfer of care unclear re possible return to midwifery & 20 \\
& Oxytocin induction & 164 \\
\hline
\end{tabular}




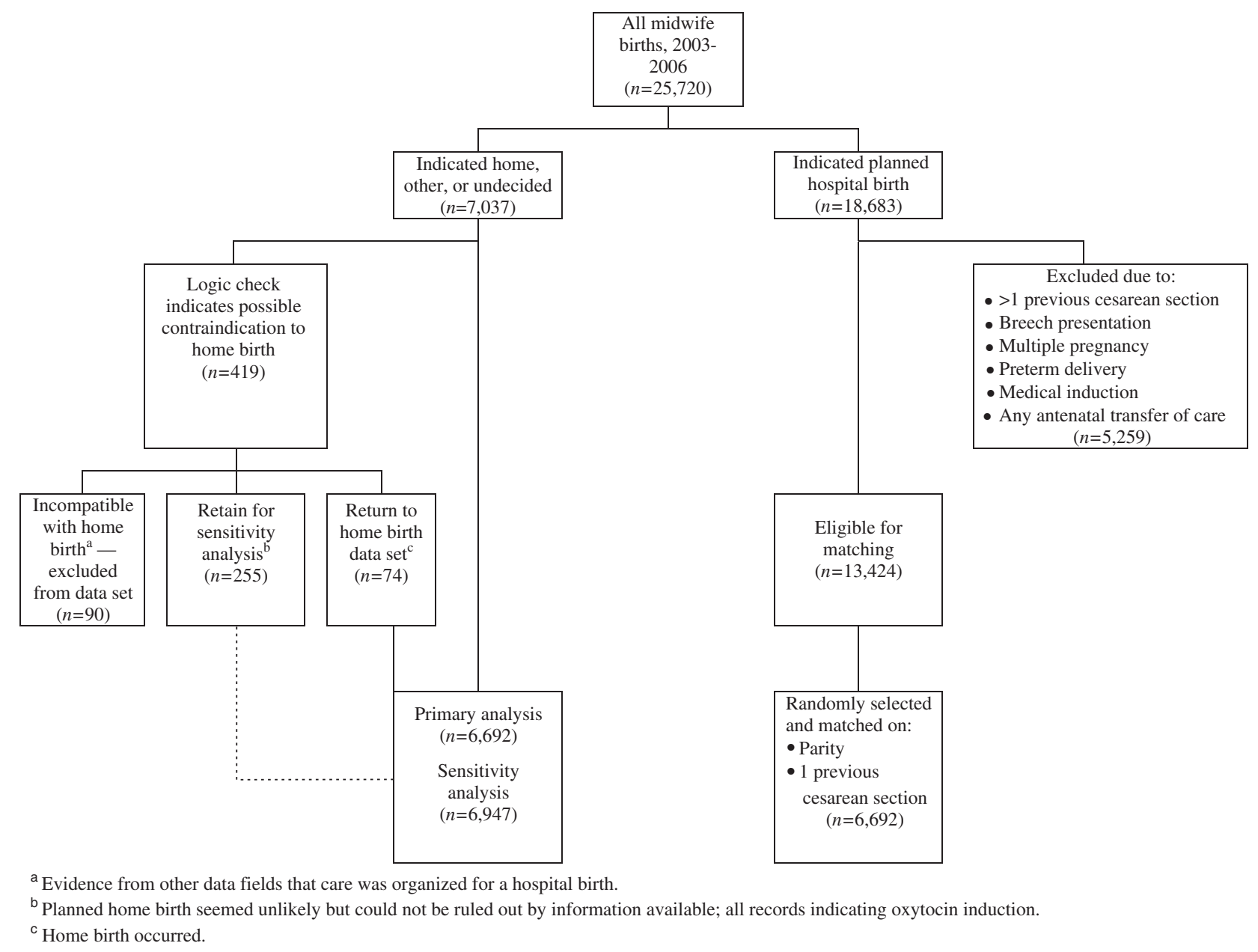

Fig. 1. Selection of included records.

this information will be documented on the client medical record. The data form provides information about the planned location of birth when labor begins, since intervening situations and changes of preference can modify the initial plan.

For this study, the planned home birth group included all client records where "planned place of birth at the outset of labor" was "home," "other out-of-hospital location" (Ontario offers no formal out-of-hospital alternative settings to home birth, such as birth centers), or "undecided," because in any of these situations the occurrence of the birth outside the hospital was a possibility. To detect possible coding errors for the planned place of birth, we carried out logic checks to identify the records with contraindications to planned home birth or records with interventions that were inconsistent with home birth (oxytocin induction of labor) or in which an antenatal transfer of care to a physician was documented. Two experienced midwives independently used an algorithm, developed a priori, to decide whether to include the record in the main analysis, permanently exclude the record, or reserve the record for the sensitivity analysis (Fig. 1, Table 1).

The comparison group was derived from the remaining records in the data set from the same time period, all of which indicated that the hospital was the planned place of birth at the outset of labor. To ensure a low-risk cohort comparable to the planned home birth cohort, we removed all the records in which a home birth would have been contraindicated (had it been planned), or in which a prelabor intervention had occurred that was inconsistent with, or unlikely at, a home birth. Thus, from the planned hospital group, we excluded the records with more than one previous cesarean section, breech presentation, multiple pregnancies, preterm delivery prior to 37 weeks' gestation, oxytocin induction of labor, prostaglandin cervical ripening, or any antenatal transfer of care to a physician.

To minimize the risk of bias, we stratified our current low-risk hospital records on parity $(0$ or $\geqslant 1)$ and on previous cesarean section (none or one), and from each 
strata selected a random sample of records matching the groups on parity and previous cesarean section (36).

\section{Outcomes}

Our primary outcome was a composite measure of perinatal and neonatal mortality or serious morbidity, defined as the presence of one or more of the following: death (stillbirth or neonatal death 0-27 days, excluding lethal anomalies and fetal demise before the onset of labor); Apgar score of less than 4 at 5 minutes of age; neonatal resuscitation requiring both positive pressure ventilations and cardiac compressions; admission to a neonatal or pediatric intensive care unit with a length of stay greater than 4 days; or birthweight less than 2,500 g. We note that although birthweight is not an outcome that can be a result of birth place, failure to screen adequately for extremes of weight can result in planning for an inappropriate place of birth. Thus, low birthweight was included as part of the composite. Perinatal or neonatal mortality cases that listed a lethal anomaly were independently reviewed by two authors blinded to group, and

Table 2. Baseline Characteristics of Women Planning Home and Hospital Birth

\begin{tabular}{|c|c|c|}
\hline Characteristic & $\begin{array}{c}\text { Planned } \\
\text { Home } \\
(\mathrm{n}=6,692) \\
\text { No. }(\%)\end{array}$ & $\begin{array}{c}\text { Planned } \\
\text { Hospital } \\
(\mathrm{n}=6,692) \\
\text { No. }(\%)\end{array}$ \\
\hline \multicolumn{3}{|l|}{ Age (yr) } \\
\hline$<25$ & $729(10.9)$ & $844(12.6)$ \\
\hline $25-34$ & $4,428(66.1)$ & $4,630(69.2)$ \\
\hline$\geqslant 35$ & $1,503(22.5)$ & $1,199(17.9)$ \\
\hline Missing & $32(0.5)$ & $19(0.3)$ \\
\hline \multicolumn{3}{|l|}{ Parity } \\
\hline 0 & $2,293(34.3)$ & $2,298(34.3)$ \\
\hline $1-4$ & $4,172(62.3)$ & $4,289(64.1)$ \\
\hline$>4$ & $221(3.3)$ & $105(1.6)$ \\
\hline Missing & $6(0.1)$ & - \\
\hline \multicolumn{3}{|l|}{ Geographical location } \\
\hline South rural & $1,022(15.3)$ & $901(13.5)$ \\
\hline South urban & $5,305(79.3)$ & $4,937(73.8)$ \\
\hline North rural & $91(1.4)$ & $192(2.9)$ \\
\hline North urban & $271(4.0)$ & $661(9.9)$ \\
\hline Missing & $3(0.0)$ & $1(0.0)$ \\
\hline \multicolumn{3}{|c|}{ Repeat Ontario midwifery client } \\
\hline Yes & $3,044(45.5)$ & $2,331(34.8)$ \\
\hline No & $3,642(54.4)$ & $4,357(65.1)$ \\
\hline Missing & $6(0.1)$ & $4(0.1)$ \\
\hline \multicolumn{3}{|l|}{ Previous cesarean section } \\
\hline 0 & $6,479(96.8)$ & $6,485(96.9)$ \\
\hline 1 & $200(3.0)$ & $207(3.1)$ \\
\hline$>1$ & $6(0.1)$ & - \\
\hline Missing & $7(0.1)$ & - \\
\hline Median gestation at booking & 11.0 & 11.0 \\
\hline Median gestation at birth & 40.0 & 40.0 \\
\hline
\end{tabular}

a consensus decision was made with respect to exclusion from the composite outcome.

Other outcomes included maternal mortality, significant morbidity, rates of intrapartum interventions, and breastfeeding. We included any maternal death from a direct obstetrical cause (as determined by a provincial coroner's review of all maternal deaths) occurring between the onset of labor and 6 weeks postpartum. Significant maternal morbidity included blood loss greater than $1,000 \mathrm{~mL}$ or bleeding requiring a consultation with a physician; any infection after onset of labor requiring a consultation with a physician; any third or fourth degree laceration; and any postpartum transfer of care to a physician. Any situation requiring a consultation or a transfer of care was deemed to be a significant outcome because the indications for consultation and/or transfer of care are well defined by the College of Midwives of Ontario. So, whereas practitioners might typically underestimate blood loss greater than $1,000 \mathrm{~mL}$, any symptomatic blood loss or transfusion would be captured in our analysis by including the consultation or transfer of care in the postpartum period.

Intrapartum interventions included rates of labor augmentation, use of any pharmaceutical pain relief, episiotomy and perineal trauma, assisted vaginal delivery, and cesarean section. Rates of infant feeding with formula supplementing breastfeeding or exclusive formula feeding were compared at 1 and 6 weeks of age.

\section{Data Analysis}

All the analyses were conducted using SPSS 15.0 (37). We used descriptive statistics to report baseline characteristics. Comparative analyses used chi-square and relative risk (RR) and 95 percent confidence intervals (CI). We removed the possible misclassified home birth records from the primary analysis and retained them for a sensitivity analysis of the primary outcome. We also conducted a subgroup analysis of nulliparas and multiparas using descriptive statistics.

\section{Results}

\section{Data Cleaning}

We found 7,037 records indicating that at the outset of labor, birth was intended to take place at home. Of these, we identified 419 records in which an intervention inconsistent with home birth was undertaken (induction with oxytocin $[n=164]$ ) or a contraindication to home birth existed (breech delivery $[n=79]$, preterm labor $[n=86])$, or an antenatal transfer of care had occurred $(n=90)$. These records were analyzed as described in Fig. 1 and Table 1, resulting in 6,692 records for the primary analysis, and 6,947 for the sensitivity analysis. 
Table 3. Comparison of Variables in Planned Home and Hospital Groups with Relative Risk Presented for Selected Outcomes

\begin{tabular}{|c|c|c|c|c|}
\hline Variable & $\begin{array}{c}\text { Planned Home } \\
(\mathrm{n}=6,692) \\
\text { No. }(\%)\end{array}$ & $\begin{array}{c}\text { Planned Hospital } \\
(\mathrm{n}=6,692) \\
\text { No. }(\%)\end{array}$ & $\mathrm{p}$ & $R R[95 \% C I]$ \\
\hline \multicolumn{5}{|l|}{ Birth } \\
\hline \multicolumn{5}{|l|}{ Actual place of birth } \\
\hline Home & $5,259(78.6)$ & $208(3.1)$ & & \\
\hline Hospital & $1,371(20.5)$ & 6,467 (96.6) & & \\
\hline Other location & $62(0.9)$ & $17(0.3)$ & & \\
\hline \multicolumn{5}{|l|}{$\begin{array}{l}\text { Ambulance transport from home } \\
\text { during or immediately after birth }\end{array}$} \\
\hline Yes & $361(5.4)$ & $44(0.7)$ & & \\
\hline No & $6,307(94.2)$ & $6,544(97.8)$ & & \\
\hline Missing & $24(0.4)$ & $104(1.5)$ & & \\
\hline \multicolumn{5}{|l|}{ Estimated intrapartum blood loss } \\
\hline$<500 \mathrm{~mL}$ & $6,048(90.4)$ & $5,909(88.3)$ & & \\
\hline $500-1000 \mathrm{~mL}$ & $568(8.5)$ & $678(10.1)$ & & \\
\hline$>1000 \mathrm{~mL}$ & $56(0.8)$ & $82(1.2)$ & 0.026 & $0.68[0.49-0.96]$ \\
\hline Missing & $20(0.3)$ & $23(0.3)$ & & \\
\hline $\begin{array}{l}\text { Consultation or transfer of care for } \\
\text { bleeding }\end{array}$ & $79(1.2)$ & $106(1.6)$ & 0.046 & $0.75[0.56-1.00]$ \\
\hline \multicolumn{5}{|l|}{ Laceration } \\
\hline Any laceration & $3,612(54.0)$ & 4, $081(61.0)$ & & \\
\hline 1st degree perineal & $1,109(16.6)$ & $1,186(17.7)$ & & \\
\hline 2nd degree perineal & $1,695(25.3)$ & $1,939(29.0)$ & & \\
\hline 3rd degree perineal & $78(1.2)$ & $123(1.8)$ & & \\
\hline 4th degree perineal & $21(0.3)$ & $22(0.3)$ & & \\
\hline Labial & $413(6.2)$ & $381(5.7)$ & & \\
\hline Vaginal & $474(7.1)$ & $542(8.1)$ & & \\
\hline $\begin{array}{c}\text { Any } 2 \text { nd }-4 \text { th degree perineal, labial } \\
\text { or vaginal tear, or episiotomy }\end{array}$ & $2,589(38.7)$ & $2,979(44.5)$ & 0.000 & $0.87[0.83-0.90]$ \\
\hline Intrapartum transfer of care & $837(12.5)$ & $1,270(19.0)$ & 0.000 & $0.66[0.61-0.71]$ \\
\hline $\begin{array}{l}\text { Postpartum transfer of care } \\
\text { Intrapartum intervention }\end{array}$ & $119(1.8)$ & $104(1.6)$ & 0.311 & $1.14[0.88-1.49]$ \\
\hline \multicolumn{5}{|l|}{ Labor induction* } \\
\hline None & $6,586(98.4)$ & $6,524(97.5)$ & & \\
\hline ARM before labor & $73(1.1)$ & $136(2.0)$ & & \\
\hline Prostaglandin & $27(0.4)$ & - & & \\
\hline Unknown/missing & $15(0.2)$ & $21(0.3)$ & & \\
\hline \multicolumn{5}{|l|}{ Labor augmentation } \\
\hline None & 4, 797 (71.7) & 4, $203(62.8)$ & & \\
\hline Any augmentation & $1,852(27.7)$ & $2,426(36.3)$ & 0.000 & $0.76[0.72-0.80]$ \\
\hline ARM & $1,496(22.4)$ & $1,889(28.2)$ & & \\
\hline Oxytocin & $551(8.2)$ & $878(13.1)$ & & \\
\hline Unknown/missing & $43(0.6)$ & $63(0.9)$ & & \\
\hline \multicolumn{5}{|l|}{ Pharmaceutical pain relief } \\
\hline None & $5,570(83.2)$ & $3,667(54.8)$ & & \\
\hline Any pharmaceutical pain relief & $1,122(16.8)$ & $3,025(45.2)$ & 0.000 & $0.37[0.35-0.39]$ \\
\hline Nitrous oxide & $221(3.3)$ & $1,206(18.0)$ & & \\
\hline Narcotic analgesia & $117(1.7)$ & $423(6.3)$ & & \\
\hline \multicolumn{5}{|l|}{ Regional anesthesia } \\
\hline Epidural & $655(9.8)$ & $1405(21.0)$ & & \\
\hline Spinal & $114(1.7)$ & $199(3.0)$ & & \\
\hline General anesthesia & $26(0.4)$ & $48(0.7)$ & & \\
\hline Local anesthesia & $191(2.9)$ & $352(5.3)$ & & \\
\hline Episiotomy & $286(4.3)$ & $393(5.9)$ & 0.000 & $0.73[0.63-0.84]$ \\
\hline \multicolumn{5}{|l|}{ Mode of delivery } \\
\hline Spontaneous vaginal & $6,146(91.8)$ & $5,852(87.4)$ & & \\
\hline Assisted vaginal & $195(2.9)$ & $293(4.4)$ & 0.000 & $0.67[0.56-0.80]$ \\
\hline Forceps & $81(1.2)$ & $141(2.1)$ & & \\
\hline Vacuum & $124(1.9)$ & $168(2.5)$ & & \\
\hline Cesarean section & $348(5.2)$ & $544(8.1)$ & 0.000 & $0.64[0.56-0.73]$ \\
\hline
\end{tabular}

* Oxytocin induction is not undertaken at home and was an exclusion for the hospital birth cohort.

$A R M=$ artificial rupture of membranes. 
Table 4. Comparison of Neonatal Variables in Planned Home and Hospital Groups with Relative Risk Presented for Selected Outcomes

\begin{tabular}{|c|c|c|c|c|}
\hline Variable & $\begin{array}{l}\text { Planned Home } \\
\qquad \begin{array}{c}(\mathrm{n}=6,692) \\
\text { No. }(\%)\end{array}\end{array}$ & $\begin{array}{c}\text { Planned Hospital } \\
(\mathrm{n}=6,692) \\
\text { No. }(\%)\end{array}$ & $\mathrm{p}$ & $R R[95 \% C I]$ \\
\hline Breech presentation & $12(0.2)$ & - & & \\
\hline Multiple birth & - & - & & \\
\hline \multicolumn{5}{|l|}{ Gestational age (wk) } \\
\hline$<37$ & $17(0.3)$ & - & & \\
\hline 37-41, 6 days & $6,555(98.0)$ & $6,638(99.2)$ & & \\
\hline$>41,6$ days & $117(1.7)$ & $54(0.8)$ & & \\
\hline Missing & $3(0.0)$ & - & & \\
\hline \multicolumn{5}{|l|}{ Birthweight (g) } \\
\hline$<2,500$ & $38(0.6)$ & $56(0.8)$ & & \\
\hline $2,500-4,000$ & $5,364(80.2)$ & $5,410(80.8)$ & & \\
\hline$>4,000$ & $1,279(19.1)$ & $1,220(18.2)$ & & \\
\hline Missing & $11(0.2)$ & $6(0.1)$ & & \\
\hline \multicolumn{5}{|l|}{ Apgar scores } \\
\hline$<4$ at $1 \mathrm{~min}$ & $89(1.3)$ & $107(1.6)$ & & \\
\hline Missing & $49(0.7)$ & $36(0.5)$ & & \\
\hline$<7$ at $5 \mathrm{~min}$ & $47(0.7)$ & $58(0.9)$ & & \\
\hline Missing & $40(0.6)$ & $34(0.5)$ & & \\
\hline \multicolumn{5}{|l|}{ Infant resuscitation } \\
\hline PPV & $432(6.5)$ & $382(5.7)$ & & \\
\hline PPV and chest compressions & $21(0.3)$ & $23(0.3)$ & & \\
\hline \multicolumn{5}{|l|}{ Significant congenital anomalies } \\
\hline None & $6,515(97.4)$ & $6,513(97.3)$ & & \\
\hline Major & $28(0.4)$ & $24(0.4)$ & & \\
\hline Minor & $140(2.1)$ & $144(2.2)$ & & \\
\hline Life threatening & $5(0.1)$ & $4(0.1)$ & & \\
\hline Unknown/missing & $4(0.1)$ & $7(0.1)$ & & \\
\hline \multicolumn{5}{|l|}{ Infant feeding at $1 \mathrm{wk}$} \\
\hline Exclusively breastfed & $6,122(91.5)$ & $5,638(84.2)$ & & \\
\hline Breastfed with supplement, or exclusively formula fed & $544(8.1)$ & $1,016(15.2)$ & 0.000 & $0.53[0.48-0.59]$ \\
\hline Unknown & $26(0.4)$ & $38(0.6)$ & & \\
\hline \multicolumn{5}{|l|}{ Infant feeding at $6 \mathrm{wk}$} \\
\hline Exclusively breastfed & $5,853(87.5)$ & $5,140(76.8)$ & & \\
\hline Breastfed with supplement, or exclusively formula fed & $620(9.3)$ & $1,260(18.8)$ & 0.000 & $0.49[0.44-0.53]$ \\
\hline Unknown/missing & $219(3.3)$ & $292(4.4)$ & & \\
\hline Any mortality & $9(0.1)$ & $9(0.1)$ & & \\
\hline Stillbirth* & $3(0.0)$ & $4(0.1)$ & & \\
\hline Neonatal mortality ${ }^{\dagger}$ & $6(0.1)$ & $4(0.1)$ & & \\
\hline Infant death $28-42$ days & - & $1(0.0)$ & & \\
\hline
\end{tabular}

*No congenital anomalies noted in either group.

${ }^{\dagger}$ Includes 2 infants with a major congenital anomaly in the planned hospital group (1 brain tumor, 1 liver cirrhosis).

$P P V=$ positive pressure ventilation.

\section{Participants}

Once the records were classified, the planned home birth group comprised 6,692 women. A sample of 6,692 women was then randomly selected and stratified for parity and one previous cesarean section from the low-risk planned hospital group for the analysis. The groups were similar on baseline characteristics (Table 2). Most women were between 25 and 34 years of age, multiparous, and lived in the southern urban part of the province. More women planning home births $(45.5 \%)$ had received care from a midwife in a previous pregnancy compared with those in the hospital birth group (34.8\%).

\section{Outcomes}

Of 6,692 women in each group, 5,259 (78.6\%) of those in the planned home birth group gave birth at home and $6,467(96.6 \%)$ of those in the planned hospital birth group gave birth in hospital (Table 3). Overall, 98.6 percent of newborns were born between 37 and 41 completed weeks of pregnancy (Table 4). The planned home birth group had more babies with a gestational age greater than 42 weeks $(1.7 \%$ vs $0.8 \%)$.

Table 5 displays the perinatal/neonatal composite outcome $(2.4 \%$ vs $2.8 \%$ RR [95\% CI]: 0.84 [0.68, 1.03]). No differences were reported in the rates of perinatal or 
Table 5. Primary Outcome Including Primary and Sensitivity Analyses

\begin{tabular}{|c|c|c|c|c|}
\hline Outcome & $\begin{array}{c}\text { Planned Home } \\
(\mathrm{n}=6,692) \\
\text { No. }(\%)\end{array}$ & $\begin{array}{c}\text { Planned Hospital } \\
(\mathrm{n}=6,690) \\
\text { No. }(\%)\end{array}$ & $\mathrm{p}$ & $R R[95 \% C I]$ \\
\hline \multicolumn{5}{|l|}{$\begin{array}{l}\text { Primary outcome: Perinatal/neonatal } \\
\text { morbidity or mortality }\end{array}$} \\
\hline Composite outcome in primary analysis* & $159(2.4)$ & $190(2.8)$ & 0.092 & $0.84[0.68-1.03]$ \\
\hline $\begin{array}{l}\text { Composite outcome in sensitivity analysis } \\
\text { (planned home birth, } n=6,947 \text { ) }\end{array}$ & $180(2.6)$ & $190(2.8)$ & 0.371 & $0.91[0.75-1.12]$ \\
\hline \multicolumn{5}{|l|}{$\begin{array}{l}\text { Composite component outcomes } \\
\text { (primary analysis) }\end{array}$} \\
\hline Perinatal/neonatal mortality & $9(0.1)$ & $6(0.1)$ & 0.600 & $1.50[0.53-4.21]$ \\
\hline Stillbirth (after onset of labor) & $3(0.0)$ & $4(0.1)$ & & \\
\hline Neonatal death $<28$ days & $6(0.1)$ & $2(0.0)$ & & \\
\hline Neonatal morbidity & $155(2.3)$ & $189(2.8)$ & 0.063 & $0.82[0.66-1.01]$ \\
\hline Birthweight $<2,500 \mathrm{~g}$ & $38(0.6)$ & $56(0.8)$ & & \\
\hline Apgar $<4$ at $5 \mathrm{~min}$ & $10(0.1)$ & $8(0.1)$ & & \\
\hline PPV and cardiac compressions & $21(0.3)$ & $23(0.3)$ & & \\
\hline NICU $>4$ days & $102(1.5)$ & $115(1.7)$ & & \\
\hline
\end{tabular}

*Two infants with a major congenital anomaly excluded from planned hospital group.

$P P V=$ positive pressure ventilation; $N I C U=$ neonatal intensive care unit.

neonatal mortality between the groups, or in the rates of serious morbidity $(2.3 \%$ vs $2.8 \%$ RR [95\% CI]: 0.82 $[0.66,1.01])$. The rate of perinatal and neonatal mortality was 1 death per 1,000 live births for both groups, with 9 in the planned home birth group and 8 in the planned hospital birth group (of which 2 had significant congenital conditions and were removed from the composite outcome). One additional death occurred between 28 and 42 days of age in the planned hospital group. With respect to infant feeding, infants born to women planning to birth at home were one half as likely to use supplemental formula feeding or be exclusively formula fed at 1 week $(8.1 \%$ vs $15.2 \%$, RR [95\% CI]: 0.53 [0.48, $0.59])$ and at 6 weeks of age $(9.3 \%$ vs $18.8 \%$, RR [95\% CI]: 0.49 [0.44, 0.53]).

No maternal deaths occurred in either group. Women in the planned home birth group experienced fewer intrapartum interventions for each specific intervention studied (induction, augmentation, pharmaceutical pain relief, episiotomy, assisted delivery), including an absolute decrease of 2.9 percent in the rate of cesarean section (5.2\% vs 8.1\%, RR [95\% CI]: 0.64 [0.56, 0.73]). Women in this group also had less perineal trauma and reduced incidence of blood loss greater than 1,000 mL. Intrapartum transfers of care from midwives to another practitioner (typically an obstetrician) were significantly fewer in the planned home birth group $(12.5 \%$ vs $19.0 \%$, RR [95\% CI]: 0.66 [0.61, 0.71]) (Table 3).

\section{Sensitivity Analysis}

As described earlier, after completing the logic checks, we excluded from our primary analysis 255 records that were identified as women who were planning a home birth. Although we judged it unlikely that these records were truly planned home births at the outset of labor, we undertook a sensitivity analysis and added them to the planned home birth group, and reanalyzed our primary outcome. Inclusion of these additional records did not change the findings (Table 5).

\section{Subgroup Analysis}

The results of the subgroup analysis are reported in Table 6. In our sample, nulliparas were less likely to deliver at home, and had higher rates of ambulance transport from home to hospital compared with multiparas planning a home birth. Compared with multiparas, nulliparas in both the planned home and hospital groups were more likely to experience outcomes such as blood loss greater than $1,000 \mathrm{~mL}$; experience $2 \mathrm{nd}$, $3 \mathrm{rd}$, or 4 th degree tears; require consultation or transfer of care; and have interventions such as augmentation, pain relief, assisted vaginal delivery, and cesarean section. The rates of intervention and outcomes among nulliparas planning home birth were similar to, or lower than, among those planning hospital births. Neonatal morbidity and mortality was similar among all subgroups. Multiparas planning home birth were most likely to be exclusively breastfeeding at 6 weeks, followed by nulliparas planning birth at home. Nulliparas planning hospital birth had the lowest rate of breastfeeding.

\section{Discussion}

As expected in a low-risk population, overall rates of intervention, maternal morbidity, and perinatal/neonatal morbidity and mortality were low for both groups. With 
Table 6. Subgroup Analysis of Selected Variables for Nulliparas and Multiparas by Planned Home and Hospital Groups

\begin{tabular}{|c|c|c|}
\hline Variable & $\begin{array}{c}\text { Planned Home } \\
\text { Nulliparas }(\mathrm{n}=2,293) \\
\text { Multiparas }(\mathrm{n}=4,393) \\
\text { No. }^{\mathrm{a}}(\%)\end{array}$ & $\begin{array}{c}\text { Planned Hospital } \\
\text { Nulliparas }(\mathrm{n}=2,298) \\
\text { Multiparas }(\mathrm{n}=4,394) \\
N_{\text {No }}{ }^{\mathrm{a}}(\%)\end{array}$ \\
\hline \multicolumn{3}{|c|}{ Actual place of birth-home } \\
\hline Nulliparas & $1,364(59.5)$ & $76(3.3)$ \\
\hline Multiparas & $3,891(88.6)$ & $132(3.0)$ \\
\hline \multicolumn{3}{|c|}{$\begin{array}{l}\text { Ambulance transport from home during or } \\
\text { immediately after birth }\end{array}$} \\
\hline Nulliparas ${ }^{\mathrm{b}}$ & $188(8.2)$ & $14(0.6)$ \\
\hline Multiparas ${ }^{c}$ & $173(3.9)$ & $30(0.7)$ \\
\hline \multicolumn{3}{|c|}{ Estimated intrapartum blood loss $>1,000 \mathrm{~mL}$} \\
\hline Nulliparas ${ }^{\mathrm{d}}$ & $29(1.3)$ & $31(1.3)$ \\
\hline Multiparas ${ }^{\mathrm{e}}$ & $27(0.6)$ & $51(1.2)$ \\
\hline \multicolumn{3}{|c|}{ Consultation or transfer of care for bleeding } \\
\hline Nulliparas & $32(1.4)$ & $39(1.7)$ \\
\hline Multiparas & $47(1.1)$ & $67(1.5)$ \\
\hline \multicolumn{3}{|c|}{$\begin{array}{l}\text { Laceration-any } 2 \text { nd }-4 \text { th degree perineal, labial, } \\
\text { or vaginal tear, or episiotomy }\end{array}$} \\
\hline Nulliparas & $1,406(61.3)$ & $1,382(60.1)$ \\
\hline Multiparas & $1,182(26.9)$ & $1,597(36.3)$ \\
\hline \multicolumn{3}{|c|}{ Intrapartum transfer of care } \\
\hline Nulliparas & $638(27.8)$ & $798(34.7)$ \\
\hline Multiparas & $197(4.5)$ & $472(10.7)$ \\
\hline \multicolumn{3}{|c|}{ Postpartum transfer of care } \\
\hline Nulliparas & $66(2.9)$ & $49(2.1)$ \\
\hline Multiparas & $53(1.2)$ & $55(1.3)$ \\
\hline \multicolumn{3}{|c|}{ Any labor augmentation } \\
\hline Nulliparas ${ }^{\mathrm{f}}$ & $817(35.8)$ & $1,038(45.5)$ \\
\hline Multiparas & $1,032(23.7)$ & $1,388(31.9)$ \\
\hline \multicolumn{3}{|c|}{ Any pharmaceutical pain relief } \\
\hline Nulliparas & $782(34.1)$ & $1,434(62.4)$ \\
\hline Multiparas & $338(7.7)$ & $1,591(36.2)$ \\
\hline \multicolumn{3}{|l|}{ Episiotomy } \\
\hline Nulliparas & $229(10.0)$ & $277(12.1)$ \\
\hline Multiparas & $57(1.3)$ & $116(2.6)$ \\
\hline \multicolumn{3}{|c|}{ Assisted vaginal delivery } \\
\hline Nulliparas & $166(7.2)$ & $221(9.6)$ \\
\hline Multiparas & $28(0.6)$ & $72(1.6)$ \\
\hline \multicolumn{3}{|c|}{ Cesarean Section } \\
\hline Nulliparas & $276(12.0)$ & 365 (15.9) \\
\hline Multiparas & $71(1.6)$ & $179(4.1)$ \\
\hline \multicolumn{3}{|c|}{ Infant feeding at $1 \mathrm{wk}$-exclusively breastfed } \\
\hline Nulliparas ${ }^{\mathrm{h}}$ & $1,996(87.4)$ & $1,825(79.9)$ \\
\hline Multiparasi & 4, $122(94.2)$ & $3,813(87.2)$ \\
\hline \multicolumn{3}{|c|}{ Infant feeding at $6 \mathrm{wk}$-exclusively breastfed } \\
\hline Nulliparas ${ }^{\mathrm{j}}$ & $1,962(89.1)$ & $1,680(76.7)$ \\
\hline Multiparas ${ }^{\mathrm{k}}$ & $3,887(91.1)$ & $3,460(82.2)$ \\
\hline \multicolumn{3}{|c|}{ Composite perinatal neonatal morbidity/mortality ${ }^{1}$} \\
\hline Nulliparas & $80(3.5)$ & $85(3.7)$ \\
\hline Multiparas & $79(1.8)$ & $105(2.4)$ \\
\hline \multicolumn{3}{|c|}{ Perinatal/neonatal mortality ${ }^{1}$} \\
\hline Nulliparas & $5(0.2)$ & $4(0.2)$ \\
\hline Multiparas & $4(0.1)$ & $2(0.1)$ \\
\hline \multicolumn{3}{|c|}{ Neonatal morbidity } \\
\hline Nulliparas & $78(3.4)$ & $84(3.7)$ \\
\hline Multiparas & $77(1.8)$ & $105(2.4)$ \\
\hline
\end{tabular}

${ }^{a}$ Denominator has been adjusted for missing data with missing data in home birth group and hospital birth group as follows: ${ }^{b} 8,35 ;{ }^{c} 16,68 ;{ }^{d} 6,6$;

${ }^{e} 14,15 ;{ }^{f} 12,15 ;{ }^{g} 31,48 ;{ }^{h} 10,15 ;{ }^{i} 16,23 ;{ }^{j} 91,107 ;{ }^{k} 127,185 ;{ }^{l} 2$ infants with a major congenital anomaly excluded from planned hospital group. 
an overall rate of maternal mortality in Canada approximately 7 per 100,000 live births, it is clear that catastrophic events in the low-risk population are very rare, and that this study cannot address this issue (38). Perinatal mortality rates in our study were 1 death per 1,000 live births in both groups. Statistics Canada reports a perinatal mortality rate of 6.7 per 1,000 in Ontario in 2003, and 6.3 in all of Canada (39). This rate, however, includes outcomes for pregnancies of all risk categories, and is not directly comparable with the low-risk term population that is reported in our study. Our findings were comparable to, or lower than, those reported in 2002 of home birth in British Columbia, Canada, where the perinatal mortality rate reported for home birth group was 3.5 per 1,000 and for a similar group of physician attended hospital births 1.3 per 1,000 (14).

We found no increase in risk of adverse perinatal and neonatal outcomes in morbidity or mortality between groups, but we found significantly lower rates of intrapartum intervention and of serious maternal morbidity in the planned home birth group compared with the planned hospital group. With respect to the cases included in the sensitivity analysis, it is possible that desire for home birth at the outset of labor (despite a contraindication) is construed at times to be a "plan" for a home birth. We judged that for some of the 419 cases, where the data file indicated that home birth was planned at the outset of labor in the presence of a clear contraindication, some midwives might have erroneously entered responses to indicate that a home birth had at some point in the pregnancy been planned or desired. We believe that our careful categorization of the two study groups, our approach to these cases, and the sensitivity analysis minimize the overestimation or underestimation of the outcome rates for the planned home birth cohort.

Although the planned hospital birth group experienced somewhat higher rates of labor augmentation, epidural use, assisted vaginal birth, and an increase in cesarean section, the women's outcomes are reassuring. In considering explanations for the very favorable outcomes of the planned home birth group, we believe it is unlikely that variations in midwifery practice are responsible. The same midwives cared for both groups of women. When midwives provide care in the home, they may use different skills to enhance normal labor and birth, but it seems unlikely that such differences would extend systematically across the number of midwives who provided care to the study women. We cannot discount the possibility of biased reporting of outcomes for the planned home birth group, but audits of midwifery data forms compared with hospital records have not shown systematic underreporting of problems for women transported from home to hospital. In addition, one or more midwives are present for each birth, and typically a student is in attendance, so several individuals contribute to completing a client record.
It is far more likely that differences are due to the women themselves, since they self-select the planned place of birth. We noted no major confounders between the two groups; however, more subtle but important differences likely exist between the women planning home and those planning hospital births. In Ontario, midwives are already caring for a self-selected subgroup of the population who has selected midwifery care over the more typical obstetrical model. Women who plan a home birth are often more motivated to avoid interventions such as epidural analgesia, which reduces the potential for other interventions compared with other women (16). A finding that supports the hypothesis of differences between the groups is the decreased rate of supplemented or formula fed infants at 6 weeks of age in the planned home birth group. It is also possible that multiparas in our sample who planned a home birth did so because they had an uncomplicated first birth, whereas those who experienced problems with previous births were more likely to choose a hospital setting. We were unable to verify this hypothesis, since we did not have access to actual medical records with detailed client histories.

It is also plausible that the setting itself influences the outcomes. Being in one's own home environment may go beyond mere comfort and enhance the very process of labor and birth. We found the 40 percent decrease in the rate of cesarean section, an absolute difference of nearly 3 percent, surprising and speculated about the possible influence of the hospital setting. Several hospitals in the province require that midwives transfer care to a physician according to institutional criteria, the result being more transfers than if criteria of the College of Midwives were followed. This factor is borne out with our finding of an increased rate of intrapartum transfer of care in the planned hospital group, and leads to a greater number of women having care in labor managed by hospital staff. Distress at losing a known midwife as the attendant, a more interventionist style of care, or both may contribute to an increase in assisted or operative births.

\section{Conclusions}

Whatever their relative balance, we conclude that multiple factors contribute to the decreased rate of interventions and of maternal morbidity we found in the group who planned home birth. Appropriate self-selection by the women themselves and good screening by midwives likely contribute to the observed results. A wellintegrated midwifery care system is known to have a positive impact on outcomes (40), and it is likely that the Ontario context of self-regulation, good integration into the health care system with access to emergency services, and consultation and transfer of care when necessary also contribute to favorable outcomes. 


\section{References}

1. College of Midwives of Ontario. Statement of Homebirth. Toronto, Canada: Author, 1994.

2. College of Midwives of Ontario. Indications for Mandatory Discussion, Consultation and Transfer of Care. (updated June 15). Toronto, Canada: Author, 2000.

3. Royal College of Obstetricians and Gynaecologists/Royal College of Midwives. Home Births. Joint statement No. 2. London: Authors, 2007.

4. Wiegers TA, Keirse MJNC, van der Zee J, Berghs GAH. Outcomes of planned home and planned hospital births in low risk pregnancies: Prospective study in midwifery practices in the Netherlands. BMJ 1996;313:1309-1313.

5. Campbell R, Macfarlane A. Where to Be Born: The Debate and the Evidence. Oxford, England: National Perinatal Epidemiology Unit, 1987.

6. Tew M. Safer Childbirth? A Critical History of Maternity Care. 2nd ed. London: Chapman and Hall, 1998.

7. Olsen O. Meta-analysis of the safety of home birth. Birth 1997;24(1):4-13.

8. Olsen O, Jewell D. Home versus hospital births. Cochrane Database Syst Rev. 1998, Issue 3. Art. No.: CD000352. DOI: 10.1002/14651858.CD000352.

9. Amelink-Verburg MP, Verloove-Vanhorick SP, Hakkenberg RMA, et al. Evaluation of 280,000 cases in Dutch midwifery practices: A descriptive study. BJOG 2008;115:570-578.

10. American College of Obstetrics and Gynecology. American College of Obstetrics and Gynecology (ACOG) Statement on Home Births. News release February 6, 2008. Accessed March 11, 2009. Available at: http://www.acog.org/from_home/publications/ press_releases/nr02-06-08-2.cfm.

11. Berghs G, Spnjaards E, Driessen L, et al. Neonatal neurological outcome after low-risk pregnancies. Eur J Obstet Gynecol Reprod Biol 1995;62:167-171.

12. Shearer JML. Five year prospective survey of risk of booking for a home birth in Essex. Br Med J 1985;291:1478-1480.

13. Mehl LE, Peterson GH, Whitt M, et al. Outcomes of elective home births: A series of 1,146 cases. J Reprod Med 1977;19:281-290.

14. Janssen PA, Lee SK, Ryan EM, et al. Outcomes of planned home births versus planned hospital births after regulation of midwifery in British Columbia. CMAJ 2002;166(3):315-323.

15. Crotty M, Ramsay AT. Smart R, Chan A. Planned home births in South Australia 1976-1987. Med J Aust 1990;153:664-671.

16. Ackermann-Liebrich U, Voegeli T, Gunter-Witt K, et al. Zurich Study Team. Home versus hospital deliveries: Follow up study of matched pairs for procedures and outcome. BMJ 1996;313:1313-1318.

17. McKenna P, Mathews T. Safety of home delivery compared with hospital delivery in the Eastern Region Health Authority in Ireland in the years 1999-2002. Ir Med J 2003;96(7):198-200.

18. Murphy PA, Fullerton J. Outcomes of planned home birth in nurse-midwifery practice: A prospective descriptive study. Obstet Gynecol 1998;92:461-470.

19. Hinds MW, Bergersen GH, Allen DT. Neonatal outcomes planned versus unplanned out-of-hospital births in Kentucky. JAMA 1985;253:1578-1582.

20. Davies J, Hey E, Reid W, Young G, Home Birth Study Steering Group. Prospective regional study of planned home birthday. BMJ 1996;313:1302-1306.

21. Ford C, Iliffe S, Franklin O. Outcome of planned home birth in an inner city practice. BMJ 1991;303:1517-1519.
22. Schneider G, Soderstrom B. Analysis of 275 planned and 10 unplanned home births. Can Fam Physician 1987;33: 1163-1171.

23. Woodcock HC, Read AW, Bower C, Stanley FJ, et al. A matched cohort study of planned home and hospital births in Western Australia 1981-1987. Midwifery 1994;10:125-135.

24. Durand AM. The safety of home birth: The farm study. Am J Public Health 1992;82(3):450-452.

25. Bastian H, Keirse M, Lancaster P. Perinatal death associated with planned home birth in Australia: Population based study. BMJ 1998;317:384-388.

26. Aikens Murphy P, Fullerton J. Outcomes of intended home births in nurse midwifery practice: A prospective descriptive study. Obstet Gynecol 1998;92(3):461-469.

27. Johnson KC, Davis BA. Outcomes of planned home birthday with certified professional midwives: Large prospective study in North America. BMJ 2005;330:1416-1422.

28. Tyson H. Outcomes of 1,001 midwife-attended home birthday in Toronto, 1983-1988. Birth 1991;18(1):14-19.

29. Woodcock HC, Read AE, Moore DJ, et al. Planned homebirths in Western Australia 1981-1987: A descriptive study. Med J Aust 1990;153:672-678.

30. Anderson RE, Aikins Murphy P. Outcomes of 11,788 planned home births attended by certified nurse-midwives: A retrospective descriptive study. J Nurse Midwifery 1995;40(6): 483-492.

31. Pang JW, Heffelfinger JD, Huang GJ, et al. Outcomes of planned home birth in Washington State: 1989-1996. Obstet Gynecol 2002;100(2):253-259.

32. Schramm WF, Barnes DE, Bakewell JM. Neonatal mortality in Missouri home births, 1978-84. Am J Public Health 1987;77(8):930-935.

33. Mori R, Dougherty M, Whittle M. An estimation of intrapartumrelated perinatal mortality rates for booked home births in England and Wales between 1994 and 2003. BJOG 2008;115: 554-559.

34. Statistics Canada. Births 2005. Statistics Canada Catalogue number 84F0210X1E (1): Table 1, Births by geography, Canada, 2004 and 2005;Accessed March 11, 2009. Available at: http://www.statcan.ca/english/freepub/84F0210XIE/84F0210XIE 2005001.pdf.

35. Perinatal Partnership Program of Eastern and Southeastern Ontario, Provincial Perinatal Surveillance System Committee. 2006 Provincial Perinatal Report. Ottawa, Canada: Author, August 5, 2008; Accessed March 11, 2009. Available at http://www.pppeso.on.ca/en/pppeso/NIDAY_Perinatal_Database_ p484.html.

36. College of Midwives of Ontario. Statement on VBAC and Choice of Birthplace. Toronto, Canada: Author, 2002.

37. SPSS Inc. SPPS Version 15.0. Chicago, Illinois: Author, 2006.

38. World Health Organisation. Maternal Mortality in 2005 -Estimates Developed by WHO, NICEF, UNFPA and The World Bank. World Health Organisation 2007;23, Annex 3: Estimates of number of maternal deaths, lifetime risk, MMR and range of uncertainty (2005). Accessed March 11, 2009. Available at www.who.int/making_pregnancy_safer/documents.

39. Statistics Canada. Deaths 2003. StatsCan Catalogue No. 84F0211XIE, Table 7: Perinatal mortality and components by geography. 2005;12:47. Accessed March 11, 2009. Available at www.statcan.gc.ca.

40. Weigers TA. Home or hospital birth: A prospective study of midwifery care in the Netherlands. Eur J Obstet Gynecol Reprod Biol 1998;79:139-141. 